\title{
Tensile Properties and Viscoelastic Model of a Polyimide Film*
}

\author{
Shengde ZHANG**, Syuhei MORI***, Masao SAKANE**, \\ Tadashi NAGASAWA**** and Kaoru KOBAYASHI**** \\ ** Department of Mechanical Engineering, Faculty of Science and Engineering, Ritsumeikan University, \\ 1-1-1, Nojihigashi, Kusatsu-shi, Shiga 525-8577, Japan \\ E-mail: shengde_zhang@hotmail.com \\ *** Department of Mechanical Engineering, Graduate School, Ritsumeikan University, \\ 1-1-1, Nojihigashi, Kusatsu-shi, Shiga 525-8577, Japan \\ **** Kyocera SLC Technologies Corporation, \\ Head Office 656 Ichimiyake Yasu, Shiga 520-2362, Japan
}

\begin{abstract}
This paper presents tensile properties of a polyimide thin film used in electronic devices. Tensile tests were performed to determine Young's modulus, proportional limit, yield stress, ultimate tensile strength and elongation of the polyimide film. Effects of strain rate and temperature on the tensile properties were discussed. There was a little effect of strain rate on Young's modulus but proportional limit, yield stress and ultimate tensile strength increased with increasing strain rate. Only elongation decreased with strain rate. Young's modulus, proportional limit, yield stress and ultimate tensile strength decreased with increasing temperature, but elongation increased. Applicability of a viscoelastic model for describing the stress-strain curves of the polyimide film was discussed.
\end{abstract}

Key words: Polyimide, Thin Film, Tensile Properties, Viscoelastic Model

\section{Introduction}

Build-up circuit board, consisting of laminated resin and copper thin films, has been widely used in various electronic devices to achieve high density mounting of electronic parts. Build-up circuit board undergoes cyclic temperature variation and the mismatch of the coefficient of thermal expansion between the different films causes cyclic thermal stress. In some cases, failure in the laminated circuit board was reported by the thermal crack initiation and propagation in the films ${ }^{(1)}{ }^{(2)}$. Numerical analysis, like finite element analysis, has been widely used to estimate the thermal stress and strain ranges in electronic devices and the ranges have been used to predict the thermal fatigue life. In this procedure, accurate tensile properties of resin films are essential for accuracy of the analysis resulting in the quality assurance of laminated circuit board. Since circuit boards in most practical electronic devices undergo temperature variation, tensile properties of resin films at actual temperature ranges are needed.

Tensile properties of conventional bulk materials are well known but they are not necessarily same as those of thin films, because the properties of thin films may vary with fabrication process, texture and thickness ${ }^{(3)-(7)}$. Therefore, tensile properties as used in practice should be measured and used for a reliable estimate of cyclic thermal stresses in electronic devices ${ }^{(8)}$. Polyimide films have been attracted attention recently in electronic industries to use as a material for resistant layers in build-up circuit board because of their excellent heat resistance and low coefficient of thermal expansion ${ }^{(9)-(11)}$. In addition, tensile 
properties of polyimide films have been extensively studied ${ }^{(12)-(16)}$. For example, Saeed et al. ${ }^{(12)}$ investigated effect of monomer structure on mechanical properties for 4 kinds of polyimide films. In other works, Deng et al. ${ }^{(13)}$ and Musto et al. ${ }^{(14)}$ studied the mechanical properties of polyimide-silica hybrid films. However, there are little researches studying the effect of temperature on tensile properties of polyimide films.

The objective of this paper is to study tensile properties of the polyimide film used in laminated circuit board. Tensile tests were conducted to obtain Young's modulus, proportional limit, yield stress, ultimate tensile strength and elongation at three strain rates at three temperatures. Effects of strain rate and temperature on the tensile properties were discussed. Applicability of a viscoelastic model for describing the stress-strain curves of the polyimide film is discussed.

\section{Experimental Procedure}

The material tested was a polyimide film called Kapton of which the molecular structural is shown in Fig. 1 and was used as received from Du Pont-TORAY Co., Ltd. The polyimide film was made by injection process, leading to orientation of polymer chains in the film. The amount of polymers oriented in the injection direction is slightly high. For that reason, specimens cut in the injection direction (ID) and in its transverse direction (TD) were tested to examine the anisotropy of the polyimide film as shown in Fig.2. In addition, removing internal stress treatment was conducted for the polyimide film after injection process. Other detailed information about the fabrication process was not shown in this paper because of commercial secret of the company.

Figure 3 shows the shape and dimensions of tensile specimen with $70 \mathrm{~mm}$ parallel length, $8 \mathrm{~mm}$ width and $25 \mu \mathrm{m}$ thickness. Two small white dots with $1 \mathrm{~mm}$ in diameter with $70 \mathrm{~mm}$ span were marked on the parallel part of the specimen to measure elongation during tensile test. Aluminum plates with $200 \mu \mathrm{m}$ thickness were glued on the both sides of the grip part of specimen to avoid breaking of the film from the grip part. Since specimen sometimes broke in loading stage of gripping, the shadow area shown in the figure was strengthened with copper sheet to protect from breaking and the protected part was cut just before starting tests.
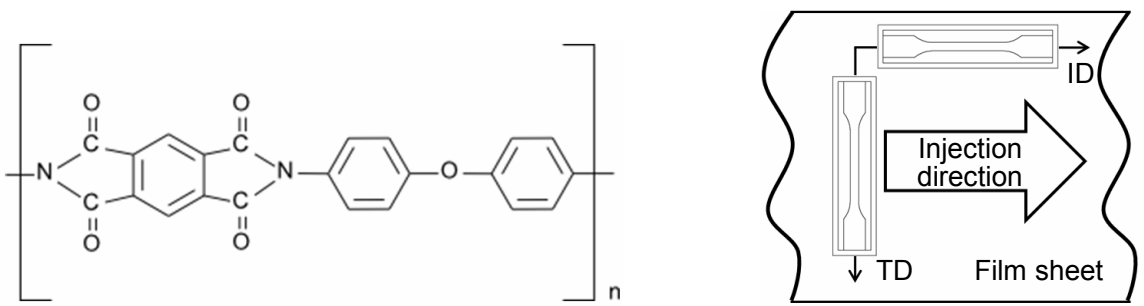

Fig.1 Molecular structural of polyimide used

Fig.2 Cutting directions of specimen

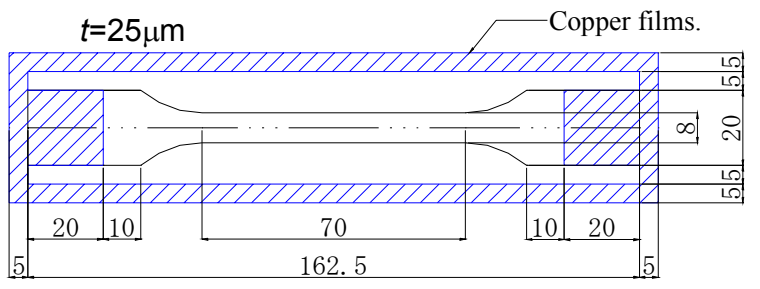

Fig.3 Shape and dimensions of specimen tested $(\mathrm{mm})$ 


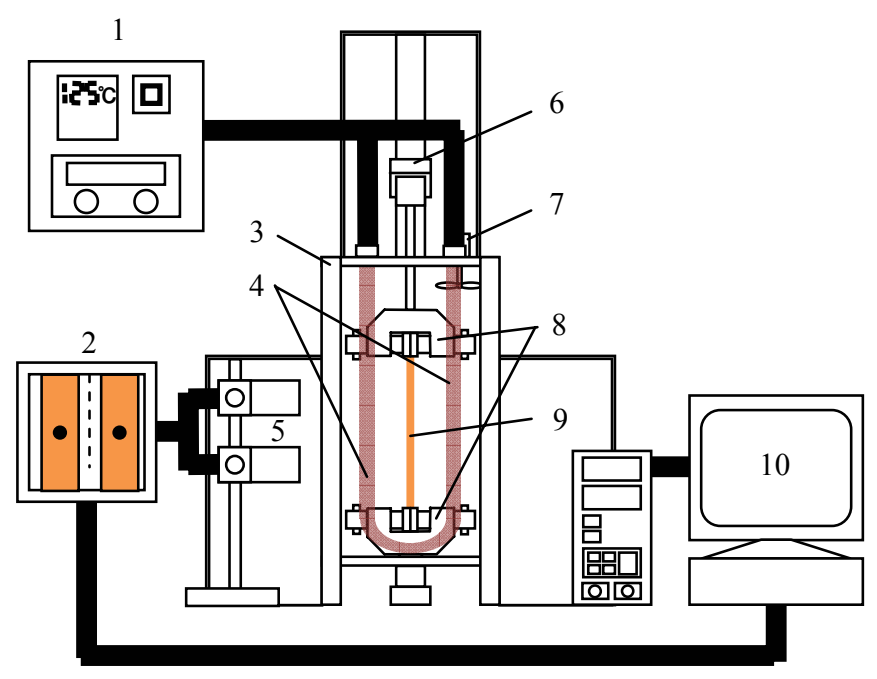

1. Temperature control

2. Image sensor

3. Furnace

4. Heater

5. CCD camera

6. Load cell

7. Fan motor

8. Grip

9. Specimen

10. Personal computer

Fig.4 Schematic of tensile apparatus

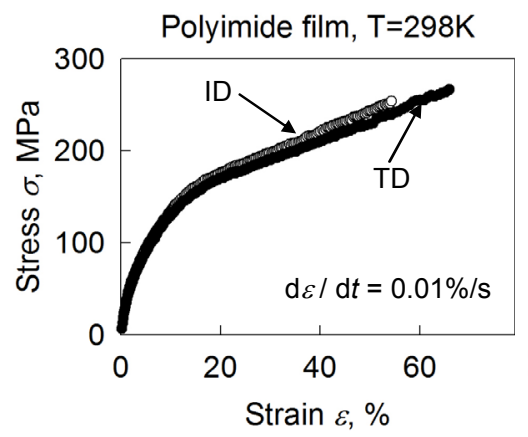

(a) Cutting direction effect
Polyimide film, $\mathrm{T}=298 \mathrm{~K}$

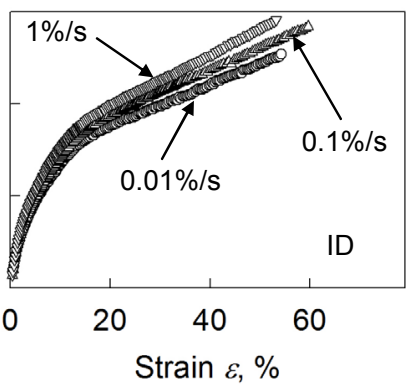

(b) Strain rate effect

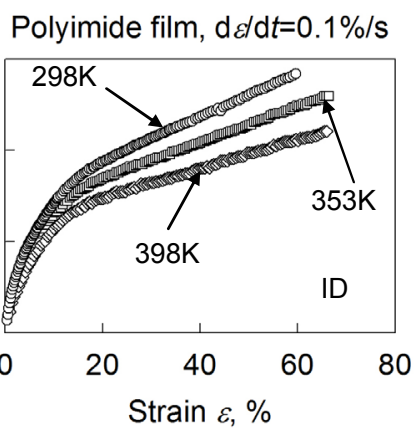

(c) Temperature effect

Fig. 5 Stress-strain curves of polyamide films

Figure 4 shows a schematic of a tensile tester (SHIMADZU/EZ Test) used in this study ${ }^{(8)}$. The resolution and the maximum capacity of load cell of the apparatus were $0.025 \mathrm{~N}$ and $500 \mathrm{~N}$, respectively. The displacement of the two dots was measured by an image sensor with two CCD cameras with $1.5 \mu \mathrm{m}$ displacement resolution. Temperature of the specimen was raised by an electric resistance furnace with $900 \mathrm{~W}$. A small fan was installed in upper part of the furnace to improve the temperature distribution of the specimen and the temperature variation in the gage part was within $1.7 \mathrm{~K}$ during test. Tensile tests were performed at strain rates of $0.01 \% / \mathrm{s}, 0.1 \% / \mathrm{s}$ and $1 \% / \mathrm{s}$ at $298 \mathrm{~K}, 353 \mathrm{~K}$ and $398 \mathrm{~K}$. Five specimens were tested under each testing condition.

\section{Results and Discussion}

\subsection{Tensile Properties}

Figure 5 depicts stress-strain curves of the polyimide film (a) in two cutting directions, (b) at three strain rates and (c) at three testing temperatures. All the polyimide films showed clear strain hardening and ruptured at the maximum stress. The stress-strain curve in the ID is nearly the same as that in the TD, Fig.5 (a). The stress increased with increasing the strain rate but decreased with increasing the temperature as shown in Fig.5 (b) and Fig.5 (c).

Table 1 summarizes tensile test results obtained in this study. The data in parenthesis show the standard deviation of the mean for each value. Figure 6 presents the variation of 
Young's modulus $(E)$ with strain rate at $298 \mathrm{~K}$ in the ID and the TD. There was a little difference in Young's modulus between the ID and the TD so that slight anisotropy of Young's modulus exists in the polyimide film. Young's moduli at $0.1 \% / \mathrm{s}$ were the largest and Young's moduli at $1 \% / \mathrm{s}$ were slightly larger than those at $0.01 \% / \mathrm{s}$. Since Young's modulus of polymer is mainly depends on the molecular structure, the strain rate has little effect on Young's modulus of the polyimide film.

Comparing Young's modulus of the polyimide film to that of bulk material with $3.1 \mathrm{~mm}$ thickness measured by Notomi et al. ${ }^{(17)}$, Young's modulus of bulk polyimide was 3.18GPa at $298 \mathrm{~K}$ and was similar to those of the film. This result means that the thickness of specimen has little effect on Young's modulus of the polyimide film, which is consistent with the reference data from company ${ }^{(18)}$. That is, Young's moduli of the polyimide films with thickness ranged from $12.5 \mu \mathrm{m}$ to $125 \mu \mathrm{m}$ were almost same.

Table 1 Summary of tensile test results

\begin{tabular}{|c|c|c|c|c|c|c|c|}
\hline$T, \mathrm{~K}$ & $\begin{array}{l}\text { Cutting } \\
\text { direction }\end{array}$ & $\begin{array}{l}\text { Strain rate } \\
d \varepsilon / d t, \% / \mathrm{s}\end{array}$ & $\begin{array}{c}\text { Young's } \\
\text { modulus } \\
E, \mathrm{GPa} \\
\end{array}$ & $\begin{array}{c}\text { Proportional } \\
\text { limit } \\
\sigma_{\mathrm{P}}, \mathrm{MPa} \\
\end{array}$ & $\begin{array}{c}\text { Yield } \\
\text { stress } \\
\sigma_{0.2}, \mathrm{MPa} \\
\end{array}$ & $\begin{array}{c}\text { Ultimate } \\
\text { tensile } \\
\text { strength } \\
\sigma_{\mathrm{B}}, \mathrm{MPa} \\
\end{array}$ & $\begin{array}{c}\text { Elongation } \\
\quad \delta, \%\end{array}$ \\
\hline \multirow{6}{*}{298} & \multirow{3}{*}{ ID } & 0.01 & $\begin{array}{c}3.19 \\
(0.23)\end{array}$ & $\begin{array}{l}33.9 \\
(2.6)\end{array}$ & $\begin{array}{l}46.6 \\
(3.0) \\
\end{array}$ & $\begin{array}{c}264 \\
(16.4)\end{array}$ & $\begin{array}{l}67.1 \\
(3.7)\end{array}$ \\
\hline & & 0.1 & $\begin{array}{c}3.73 \\
(0.12)\end{array}$ & $\begin{array}{l}33.1 \\
(0.9)\end{array}$ & $\begin{array}{l}50.9 \\
(0.7)\end{array}$ & $\begin{array}{l}300 \\
(6.7)\end{array}$ & $\begin{array}{l}64.3 \\
(3.5) \\
\end{array}$ \\
\hline & & 1.0 & $\begin{array}{c}3.32 \\
(0.20) \\
\end{array}$ & $\begin{array}{l}43.3 \\
(2.5) \\
\end{array}$ & $\begin{array}{l}61.3 \\
(2.1) \\
\end{array}$ & $\begin{array}{l}309 \\
(8.0) \\
\end{array}$ & $\begin{array}{l}59.2 \\
(1.6) \\
\end{array}$ \\
\hline & \multirow{3}{*}{ TD } & 0.01 & $\begin{array}{c}3.21 \\
(0.10)\end{array}$ & $\begin{array}{l}31.8 \\
(1.3)\end{array}$ & $\begin{array}{l}44.0 \\
(1.7)\end{array}$ & $\begin{array}{c}260 \\
(12.7)\end{array}$ & $\begin{array}{l}64.5 \\
(2.0)\end{array}$ \\
\hline & & 0.1 & $\begin{array}{c}3.56 \\
(0.14) \\
\end{array}$ & $\begin{array}{l}34.4 \\
(1.6) \\
\end{array}$ & $\begin{array}{l}50.8 \\
(1.4) \\
\end{array}$ & $\begin{array}{c}279 \\
(10.8) \\
\end{array}$ & $\begin{array}{l}60.9 \\
(4.6) \\
\end{array}$ \\
\hline & & 1.0 & $\begin{array}{c}3.19 \\
(0.16)\end{array}$ & $\begin{array}{l}47.5 \\
(2.9)\end{array}$ & $\begin{array}{l}61.5 \\
(1.4)\end{array}$ & $\begin{array}{l}294 \\
(9.4)\end{array}$ & $\begin{array}{l}60.2 \\
(4.1)\end{array}$ \\
\hline \multirow{2}{*}{353} & ID & 0.1 & $\begin{array}{c}2.87 \\
(0.09)\end{array}$ & $\begin{array}{l}32.6 \\
(1.4) \\
\end{array}$ & $\begin{array}{l}41.8 \\
(2.0) \\
\end{array}$ & $\begin{array}{c}263 \\
(17.7)\end{array}$ & $\begin{array}{l}67.2 \\
(8.6) \\
\end{array}$ \\
\hline & TD & 0.1 & $\begin{array}{c}3.07 \\
(0.11)\end{array}$ & $\begin{array}{l}32.1 \\
(0.6)\end{array}$ & $\begin{array}{l}42.1 \\
(1.0) \\
\end{array}$ & $\begin{array}{c}253 \\
(16.4)\end{array}$ & $\begin{array}{l}67.7 \\
(9.2) \\
\end{array}$ \\
\hline \multirow{2}{*}{398} & ID & 0.1 & $\begin{array}{c}2.59 \\
(0.18) \\
\end{array}$ & $\begin{array}{l}30.1 \\
(0.7)\end{array}$ & $\begin{array}{l}38.8 \\
(1.1)\end{array}$ & $\begin{array}{c}235 \\
(19.8)\end{array}$ & $\begin{array}{c}70.4 \\
(11.0)\end{array}$ \\
\hline & TD & 0.1 & $\begin{array}{c}2.42 \\
(0.09)\end{array}$ & $\begin{array}{l}28.3 \\
(0.6)\end{array}$ & $\begin{array}{l}39.6 \\
(1.6)\end{array}$ & $\begin{array}{c}228 \\
(11.6)\end{array}$ & $\begin{array}{l}73.1 \\
(8.7)\end{array}$ \\
\hline
\end{tabular}

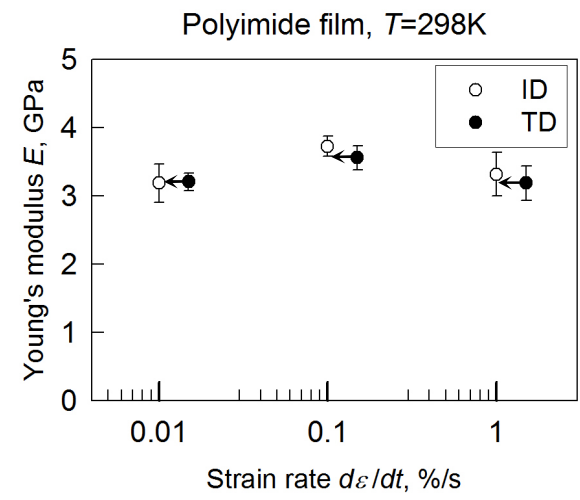

Fig.6 Variation of $E$ with strain rate

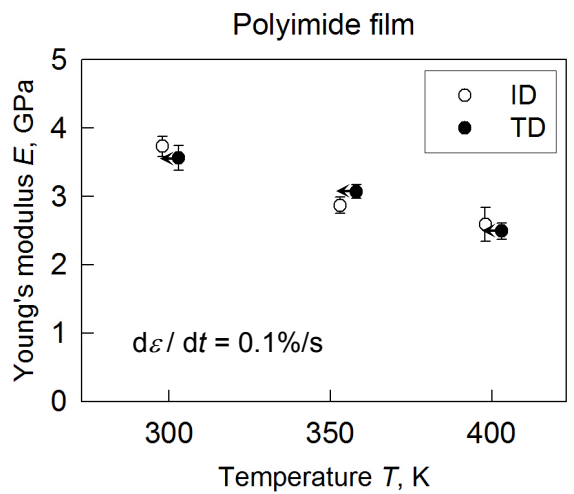

Fig.7 Variation of $E$ with temperature 


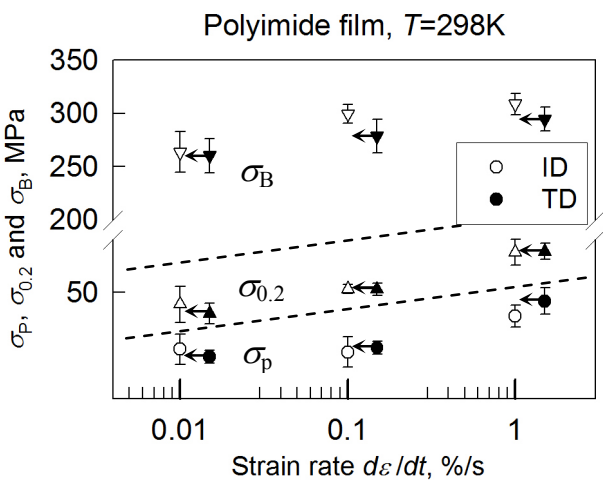

(a) Strain rate

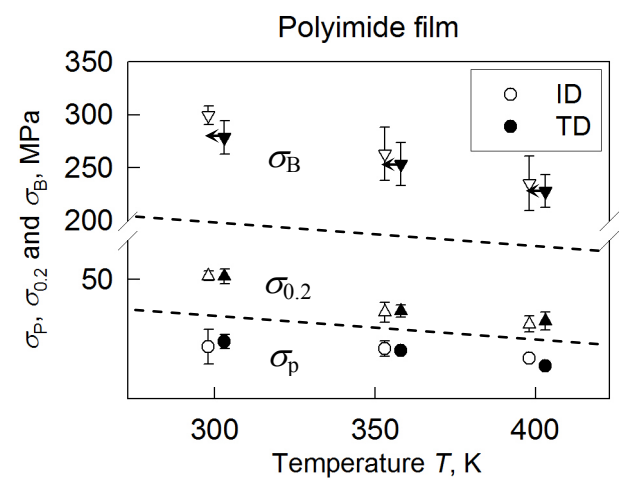

(b) Temperature

Fig.8 Variations of $\sigma_{\mathrm{p}}, \sigma_{0.2}$ and $\sigma_{\mathrm{B}}$ with (a) strain rate and (b) temperature

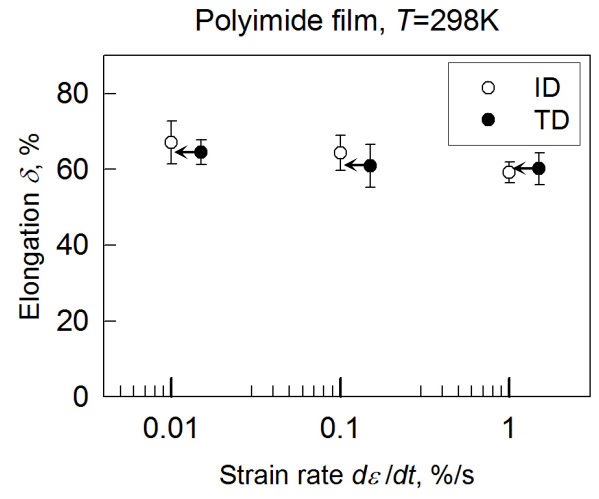

(a) Strain rate

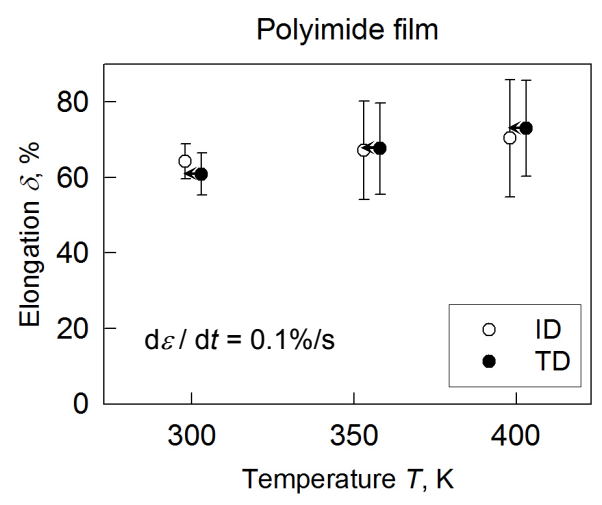

(b) Temperature

Fig.9 Variation of elongation with (a) strain rate and (b) temperature

Figure 7 plots Young's modulus against testing temperature at $0.1 \% / \mathrm{s}$ in the ID and the TD. Young's modulus decreased monotonically with the testing temperature in both the ID and the TD. This results from that the thermal activation process of molecular increases with increasing of temperature.

Figure 8 shows variations of proportional limit $\left(\sigma_{\mathrm{p}}\right)$, yield stress $\left(\sigma_{0.2}\right)$ and ultimate tensile strength $\left(\sigma_{\mathrm{B}}\right)$ in the ID and the TD with (a) strain rate at $298 \mathrm{~K}$ and (b) testing temperature at $0.1 \% / \mathrm{s}$. Proportional limits and yield stresses in the ID were comparable to those in the TD but ultimate tensile strengths in the ID were somewhat larger than those in the TD, because the amount of polymers oriented in the ID is slightly higher than that in the TD. Since the ultimate tensile strength of bulk polymer was about $88 \mathrm{MPa}{ }^{(17)}$, ultimate tensile strengths of the polyimide film were larger than that of the bulk polyimide. Ultimate tensile strength of polyimide film decreases with increasing the thickness of the film, which is consistent with the result of other report ${ }^{(18)}$.

The proportional limit, yield stress and ultimate tensile strength increased with the strain rate and decreased with the testing temperature. Increasing strain rate has the same effect on the proportional limit, yield stress and ultimate tensile strength as decreasing temperature, which can be easy explained by the thermal activation process of molecular.

In order to discuss the effects of strain rate and testing temperature on elongation, the elongations in the ID and the TD are plotted against the strain rate at $298 \mathrm{~K}$ and the testing temperature at $0.1 \%$ in Figs.9 (a) and (b), respectively. The elongations in the ID were mostly the same as those in the TD at all the tests, indicating no anisotropy of the polyimide film in elongation. The elongation of bulk polyimide was more than $100 \%{ }^{(17)}$ so the elongations of all the polyimide films were smaller than that of the bulk polyimide. In addition, the elongations slightly decreased with the strain rate and significantly increased with the temperature. 


\subsection{Viscoelastic model}

A viscoelastic model ${ }^{(19)}$ was used to describe the stress-strain curves of the polyimide film obtained in this study. This paper employed 3-element Maxwell model consisting of two spring elements and a dashpot element as shown in Fig.10 from its simplicity and easiness to apply in numerical analysis, like finite element analysis. Stress response for the 3-element Maxwell model at a constant strain rate $(C)$ is given by the following equation.

$$
\sigma=C \eta\left(1-e^{-\frac{k_{2}}{\eta} \frac{\varepsilon}{C}}\right)+k_{1} \varepsilon, C=\frac{d \varepsilon}{d t}
$$

$k_{1}$ and $k_{2}$ are the spring constants of the two spring elements, $\eta$ the viscosity constant of the dashpot element and $t$ the time.

Figure 11 presents the method of determining the constants in the 3-element Maxwell model. Eq. (1) is reduced to simple equation below at high strain regions in the stress-strain curve.

$$
\sigma=C \eta+k_{1} \varepsilon, C=\frac{d \varepsilon}{d t}
$$

Therefore, $k_{1}$ and $\eta$ is easily calculated by the following equation.

$$
k_{1}=\tan \theta, \quad \eta=\frac{D}{C}
$$

$k_{2}$ is determined by the regression analysis to have the best fitting of the data.

Table 2 lists the values of $k_{1}, k_{2}$ and $\eta$ in the 3-element Maxwell model under each testing condition performed here. Note that only $k_{2}$ is influenced by the testing temperature but is not by the strain rate. The cutting direction has also no influence on $k_{2}$. Figures 12 (a) and (b) show the variations of $k_{1}$ with strain rate and temperature, respectively. $k_{1}$ linearly increased with strain rate and decreased with increasing testing temperature. The linear relationship is expressed by the following equation.

$$
k_{1}=\left(C_{1} \frac{d \varepsilon}{d t}+C_{2}\right) \exp \left(\frac{\Delta Q_{1}}{R T}\right)
$$

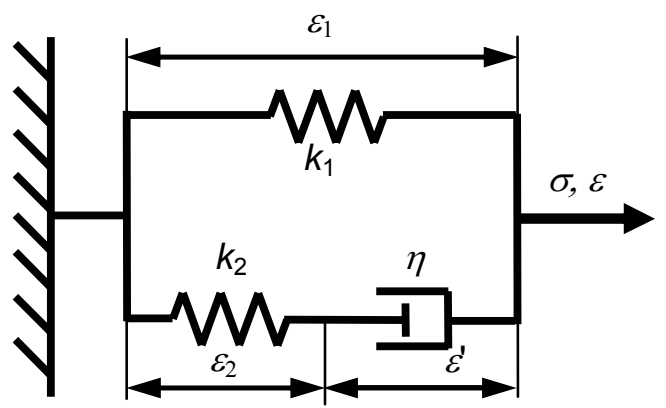

Fig.10 3-element Maxwell model

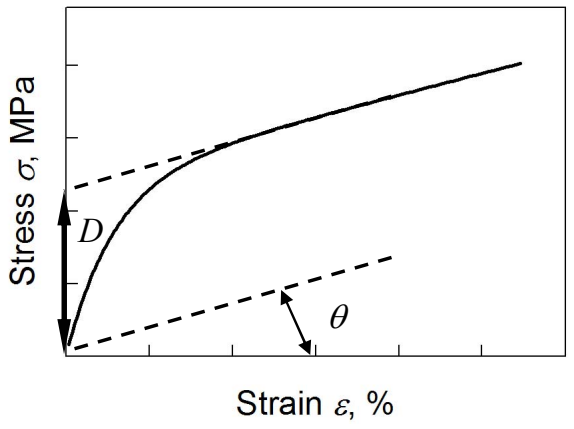

Fig. 11 Method for determining the constants in the model 
Figure 13 plots $k_{2}$ against temperature at $0.1 \% / \mathrm{s}$ in the ID. $k_{2}$ decreased with testing temperature and the relationship is equated as follow,

$$
k_{2}=C_{3} \exp \left(\frac{\Delta Q_{2}}{R T}\right)
$$

The variation of $\eta$ with strain rate and temperature are presented in Figs.14 (a) and (b), respectively. $\eta$ is almost inversely related with strain rate and is decreased with testing temperature. $\eta$ is therefore equated below,

$$
\eta=C_{4}\left(\frac{d \varepsilon}{d t}\right)^{-0.98} \exp \left(\frac{\Delta Q_{3}}{R T}\right)
$$

\begin{tabular}{|c|c|c|c|c|c|}
\hline$T, \mathrm{~K}$ & $\begin{array}{l}\text { Cutting } \\
\text { direction }\end{array}$ & $\begin{array}{l}\text { Strain rate } \\
d \varepsilon / d t, \% / \mathrm{s}\end{array}$ & $\begin{array}{c}\text { Spring constant } \\
k_{1}, \mathrm{MPa}\end{array}$ & $\begin{array}{c}\text { Spring constant } \\
k_{2}, \mathrm{MPa}\end{array}$ & $\begin{array}{c}\text { Viscosity constant } \\
\eta, \mathrm{GPa} \cdot \mathrm{s}\end{array}$ \\
\hline \multirow{6}{*}{298} & \multirow{3}{*}{ ID } & 0.01 & 231 & 2860 & 1280 \\
\hline & & 0.1 & 241 & 2860 & 140 \\
\hline & & 1.0 & 286 & 2860 & 13.9 \\
\hline & \multirow{3}{*}{ TD } & 0.01 & 210 & 2860 & 1270 \\
\hline & & 0.1 & 227 & 2860 & 141 \\
\hline & & 1.0 & 249 & 2860 & 14.4 \\
\hline \multirow{2}{*}{353} & ID & 0.1 & 197 & 2510 & 129 \\
\hline & TD & 0.1 & 175 & 2510 & 134 \\
\hline \multirow{2}{*}{398} & ID & 0.1 & 153 & 2110 & 120 \\
\hline & TD & 0.1 & 145 & 21110 & 116 \\
\hline
\end{tabular}

Table 2 Values of $k_{1}, k_{2}$ and $\eta$ in 3-element Maxwell model

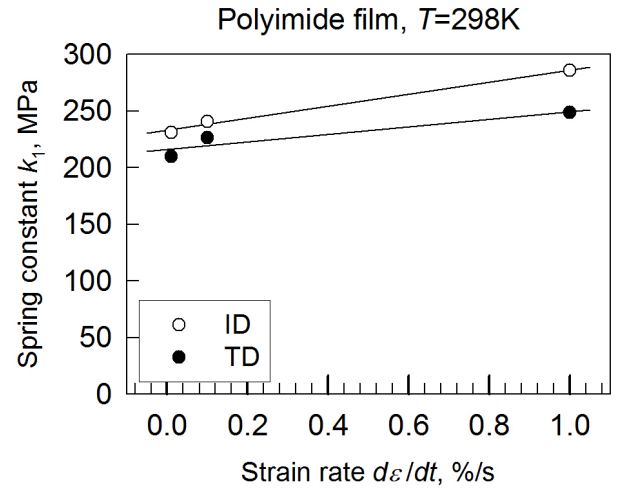

(a) Strain rate

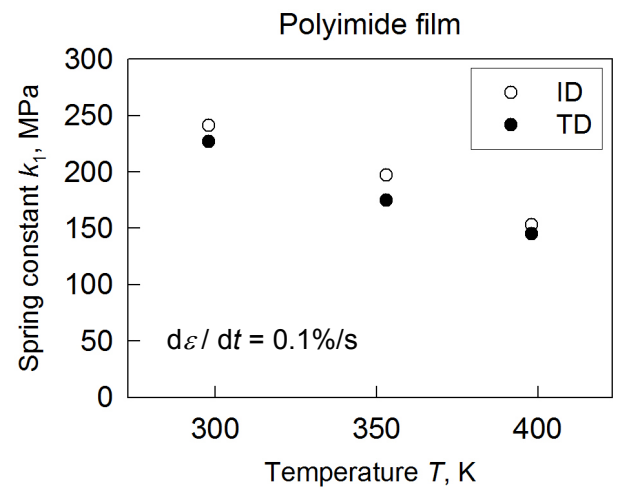

(b) Temperature

Fig. 12 Variation of $k_{1}$ with (a) strain rate at $298 \mathrm{~K}$ and (b) temperature at $0.1 \% / \mathrm{s}$

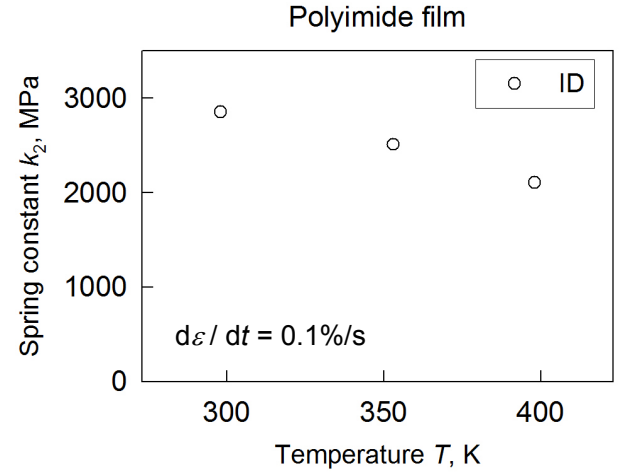

Fig.13 Variation of $k_{2}$ with temperature at $0.1 \% / \mathrm{s}$ 
Table 3 Constants in Eq. (7)

\begin{tabular}{|c|c|c|c|c|c|c|c|}
\hline $\begin{array}{c}\text { Cutting } \\
\text { direction }\end{array}$ & $\begin{array}{c}C_{1}, \\
\mathrm{MPa} \cdot \mathrm{s}\end{array}$ & $\begin{array}{c}C_{2}, \\
\mathrm{MPa}\end{array}$ & $\begin{array}{c}C_{3}, \\
\mathrm{MPa}\end{array}$ & $\begin{array}{c}C_{4}, \\
\mathrm{MPa}\end{array}$ & $\begin{array}{c}\Delta Q_{1}, \\
\mathrm{~J} / \mathrm{mol}\end{array}$ & $\begin{array}{c}\Delta Q_{2}, \\
\mathrm{~J} / \mathrm{mol}\end{array}$ & $\begin{array}{c}\Delta Q_{3}, \\
\mathrm{~J} / \mathrm{mol}\end{array}$ \\
\hline $\mathrm{ID}$ & 921 & 40.1 & 898 & 82.9 & 4360 & 2900 & 1500 \\
\hline $\mathrm{TD}$ & 570 & 37.0 & 898 & 79.6 & 4370 & 2900 & 1800 \\
\hline
\end{tabular}

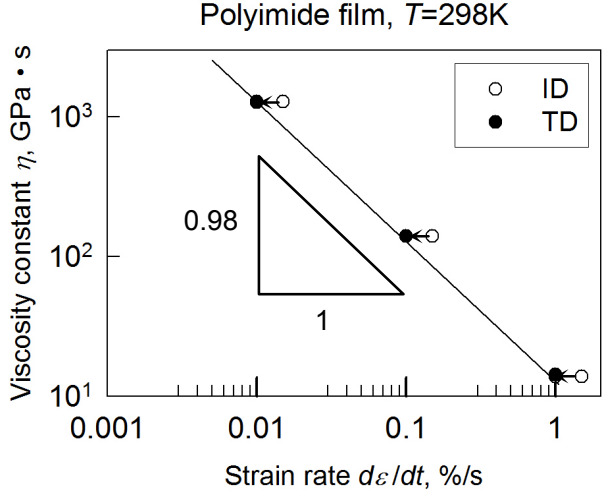

(a) Strain rate

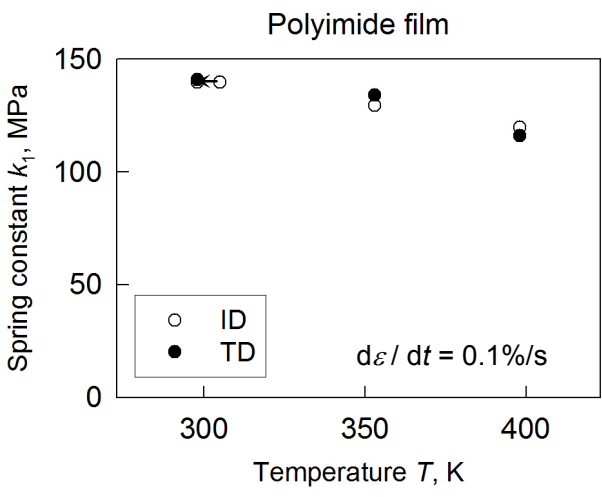

(b) Temperature

Fig.14 Variation of $\eta$ (a) strain rate at $298 \mathrm{~K}$ and (b) temperature at $0.1 \% / \mathrm{s}$

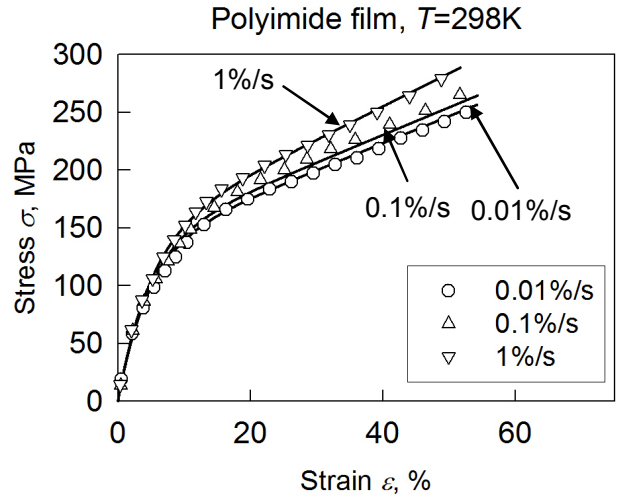

(a) Strain rate effect

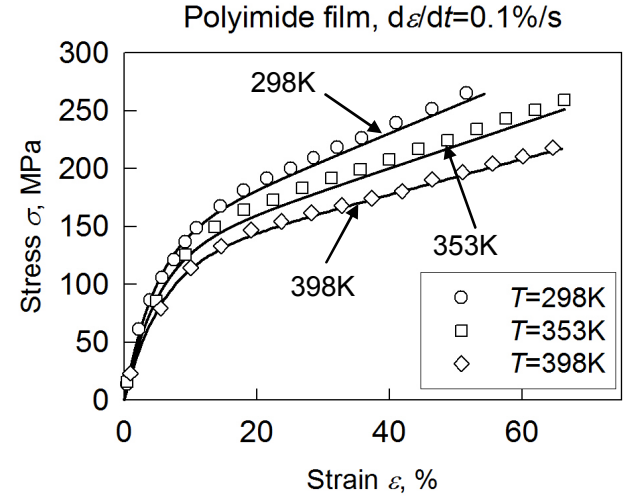

(b) Temperature effect

Fig. 15 Comparison of stress-strain curves between test data and the model in the ID

Substituting Eqs. (4), (5) and (6) into Eq. (1) gives the stress-strain relationship of the 3-element Maxwell model as follow.

$$
\sigma=C_{4}\left(\frac{d \varepsilon}{d t}\right)^{0.02} \exp \left(\frac{\Delta Q_{3}}{R T}\right)\left(1-e^{-\frac{C_{3} \varepsilon}{C_{4}\left(\frac{d \varepsilon}{d t}\right)^{0.02}} \exp \left(\frac{\Delta Q_{2}-\Delta Q_{3}}{R T}\right)}\right)+\left(C_{1} \frac{d \varepsilon}{d t}+C_{2}\right) \exp \left(\frac{\Delta Q_{1}}{R T}\right) \varepsilon
$$

Table 3 lists values of the constants in Eq. (7).

In order to check the accuracy of estimating the stress-strain relationship by Eq. (7), Figure 15 compares predicted stress-strain curves by Eq. (7) with the experimental data at three strain rates and three testing temperatures in the ID. Predicted curves were indicated by the solid lines in the figure. The predicted curves were almost same as those of the experimental data, although the predicted stresses were slightly smaller than those of the experiment at $298 \mathrm{~K}$ and $0.1 \%$ s. The results indicate that the 3 -element Maxwell model applied in this study satisfactorily describes the stress-strain curve of the polyimide film. 


\section{Conclusions}

(1) There was little anisotropy of Young's modulus, proportional limit, yield stress, ultimate tensile strength and elongation in the polyimide film used in this study. Young's modulus of the polyimide film was similar to that of the bulk polyimide. Ultimate tensile strength of the film was larger than that of the bulk polyimide, but elongation was smaller.

(2) There was a little effect of strain rate on Young's modulus but proportional limit, yield stress and ultimate tensile strength increased with increasing strain rate. Only elongation decreased with strain rate. Young's modulus, proportional limit, yield stress and ultimate tensile strength decreased with increasing temperature, but elongation increased.

(3) A 3-element Maxwell viscoelastic model consisting of two spring elements and a dashpot element was applied. The model satisfactorily described the stress-strain curve of the polyimide film.

\section{References}

(1) Tsukada, Y., Introduction of build-up circuit board (in Japanese), (1998), p. 101, Nikkan Kogyo Shimbun Ltd.

(2) Sakane, M., New Challenges for Thermo-Mechanical Fatigue III: Thermo-Mechanical Fatigue in Electronic Devices, Journal of the Society of Materials Science Japan, Vol.56, No.3 (2007), pp.302-308.

(3) Hashimoto, K., Sakane, M., and Ohnami, M., Young's Modulus of Thin Films Measured by High Resolution Three-Points Bending Machine, Transactions of the ASME, Journal of Mechanics and Materials for Electronic Packaging, Vol.187 (1994), pp.57-62.

(4) Cheng, Y.W., Read, D.T., McColskey, J.D., and Wright, J.E., A Tensile-Testing Technique for Micrometer-Sized Free-Standing Thin Films. Thin Solid Films, Vol.484 (1995), pp.426-432.

(5) Arai, M., and Ogata, T., Development of Small Fatigue Testing Machine for Film Materials, Transactions of the Japan Society of Mechanical Engineering, Series A, Vol.68, No.669 (2002), pp.801-806.

(6) Hong, S.H., Kim, K.S., Kim, Y.M., Hahn, J.H., Lee, C.S., and Park, J.H., Characterization of Elastic Moduli of $\mathrm{Cu}$ Thin Films using Nanoindentation Technique, Composite Science and Technology, Vol.65 (2005), pp.1401-1408.

(7) Fukushi, M., Miyata, H., and Murakami, A., Development on the Tensile Fatigue Test Apparatus and Strength Evaluation of Thin Metal Film, Transactions of the Japan Society of Mechanical Engineering, Series A, Vol.72, No.718 (2006), pp.880-885.

(8) Zhang, S., Oka, M., Nagasawa, T., Terada, K., Kobayashi, K., and Sakane, M., Tensile Properties of Polyamide Thin Films for Electronic Devices, Journal of the Society of Materials Science Japan, Vol.60, No.2 (2011), pp.167-173.

(9) Bessonov, M.I., and Zubkov, V.A., Polyamic acids and polyimides: synthesis, transformation and structure, (1993), Boca Raton: CRC Press.

(10) Gosh, M., and Mittal, K.L, Polyimides: fundamentals and applications, (1996), New York: Marcel Dekker.

(11) Feger, C., Polyimides: trends in materials and applications, (1996), New York: Society of Plastic Engineers.

(12) Saeed, M.B., and Zhan, M., Effects of Monomer Structure and Imidization Degree on Mechanical Properties and Viscoelastic Behavior of Thermoplastic Polyimide Films, European Polymer Journal, Vol.42 (2006), pp.1844-1854.

(13) Deng, Y., Wu, M., Liu, X., and Gu, Y., Novel Inorganic Morphologies Formed in Polyimide/Silica Hybrid Films, European Polymer Journal, Vol.46 (2010), pp.2255-2260.

(14) Musto, P., Ragosta, G., Scarinzi, G., and Mascia, L., Polyimide-silica Nanocomposites: 
Spectroscopic, Morphological and Mechanical Investigations, Polymer, Vol.45 (2004), pp.1697-1706.

(15) Agag, T., Koga, T., and Takeichi, T., Studies on Thermal and Mechanical Properties of Polyimide-clay Nanocomposites, Polymer, Vol.42 (2001), pp.3399-3408.

(16) Shimamura, H., and Nakamura, T., Mechanical Properties Degradation of Polyimide Films Irradiated by Atomic Oxygen, Polymer Degradation and Stability, Vol.94 (2009), pp.1389-1396.

(17) Notomi, M., Inaba, H., Kishimoto, K., Shibuya, T., Morita, A., and Yoshida, Y., The Effect of Molecular Weight on Tensile Property and Fracture Toughness of the Polyimide Resin, Transactions of the Japan Society of Mechanical Engineering, Series A, Vol.65, No.629 (1999), pp.67-71.

(18) Du Pont-TORAY Co., Ltd. "Kapton". (online), available from $<$ http://www.td-net.co.jp/products/download/documents/kapton2007.pdf>, (accessed 2012-02-02)

(19) Tsukamoto, M., Theoretical solutions for response of visco-elastic body under constant strain rate loading, Bulletin of Educational Department University of Kumamoto, Vol.44 (1995), pp.167-179. 